\title{
Estabilidade e estudo de penetração cutânea in vitro da rutina veiculada em uma emulsão cosmética através de um modelo de biomembrana alternativo
}

\author{
André Rolim Baby ${ }^{1 *}$, Carlos Alberto Haroutiounian-Filho', Fernanda Daud Sarruf', \\ Carlos Roberto Tavante-Júnior ${ }^{1}$, Claudinéia Aparecida Sales de Oliveira Pinto ${ }^{1}$, Vivian Zague', \\ Elizabeth Pinheiro Gomes Arêas' ${ }^{2}$, Telma Mary Kaneko', Maria Valéria Robles Velasco'
}

${ }^{1}$ Departamento de Farmácia, Faculdade de Ciências Farmacêuticas, Universidade de São Paulo, ${ }^{2}$ Departamento de Química Fundamental, Instituto de Química, Universidade de São Paulo

*Correspondência:

André Rolim Baby

Laboratório de Cosmetologia

Departamento de Farmácia

Faculdade de Ciências Farmacêuticas - USP

Av. Prof. Lineu Prestes, n. 580, bl. 13/ 15, Conjunto das Químicas, Cidade Universitária

05508-900 - São Paulo - SP, Brasil

E-mail: andrerb@usp.br
A rutina é empregada como antioxidante e na prevenção da fragilidade capilar. Estudos de penetração in vitro através da pele humana seria a situação ideal, entretanto, há dificuldades de sua obtenção e manutenção de sua viabilidade. Entre os demais modelos de membrana, a muda de pele de cobra se apresenta como estrato córneo puro, fornecendo barreira similar ao humano e é obtida sem a morte do animal. Os objetivos desta pesquisa foram desenvolver e avaliar a estabilidade de uma emulsão cosmética contendo rutina e, como promotor de penetração cutânea, o propilenoglicol; e avaliar a penetração e a retenção cutânea in vitro da referida substância ativa da formulação, empregando um modelo de biomembrana alternativo. A emulsão foi desenvolvida com rutina e propilenoglicol, ambos a 5,0\% p/p. Quantificou-se a rutina das emulsões por espectrofotometria a 361,0 $\mathrm{nm}$, método previamente validado. A penetração e retenção cutânea in vitro foram realizadas em células de difusão vertical com muda de pele de cobra de Crotalus durissus, como modelo de biomembrana alternativo, é água destilada e álcool etílico absoluto 99,5\% (1:1), como fluido receptor. $O$ experimento foi conduzido em um periodo de seis horas, a 37,0 \pm $0,5{ }^{\circ} \mathrm{C}$ e agitação constante de $300 \mathrm{rpm}$. Empregou-se o método espectrofotométrico validado a 410,0 nm para a quantificação da rutina após penetração e retenção cutânea. A emulsão não promoveu a penetração cutânea da rutina através da muda de pele de $\mathrm{C}$. durissus, retendo 0,931 $\pm 0,0391 \mu \mathrm{g}$ de rutina/mg de muda de pele de cobra. Nas condições de armazenamento a $25,0 \pm 2,0^{\circ} \mathrm{C} ; 5,0 \pm$ $0,5^{\circ} \mathrm{Ce} 45,0 \pm 0,5^{\circ} \mathrm{C}$, a emulsão apresentou-se quimicamente estável durante 30 dias. De acordo com os resultados, a emulsão não favoreceu a penetração cutânea da rutina, mas apenas sua retenção no estrato córneo de C. durissus, condição considerada estável no periodo de 30 dias.
Unitermos

- Teste de estabilidade acelerada

- Emulsão

- Propilenoglicol

- Muda de pele de cobra

- Penetração cutânea/ estudo in vitro

- Rutina 


\section{INTRODUÇÃO}

A função essencial da pele é a proteção do organismo frente a diversidades do meio externo, como: agentes físicos, químicos e biológicos; microrganismos patogênicos e radiações. A pele humana intacta apresenta-se como uma eficiente barreira contra a penetração e permeação de substâncias exógenas. O que representa uma proteção ao ser humano se torna um fator limitante na ação das substâncias de atividade terapêutica e cosmética aplicadas topicamente (Hadgraft, 2001; Hadgraft, 2004; Williams, Barry, 2004).

O estudo da penetração e permeação cutânea de princípios ativos através da pele pode apresentar como primeiro fator limitante a epiderme, em especial o estrato córneo (EC), devido sua função barreira e por ser a primeira camada de contato com o meio externo (Moser et al., 2001; Baby et al., 2008).

A eficácia de produtos farmacêuticos ou cosméticos apresentando em sua composição princípios ativos funcionais é dependente da penetração limitada destes na pele. Os métodos existentes que promovem aumento deste processo se fundamentam (1) no emprego de promotores de absorção; (2) no estudo profundo das características químicas e físico-químicas das substâncias ativas e a possibilidade do emprego de seus derivados quando estas forem desfavoráveis; (3) utilização de sistemas veiculados de liberação, como microemulsão, ciclodextrinas, nanossomas, lipossomas ou formulações supersaturadas e; (4) a ação de agentes promotores físicos de penetração, como iontoforese, sonoforese e eletroporação (Bentley et al., 1997; Guy et al., 2000; Naik, Kalia, Guy, 2000).

A rutina (3-o-rutinosídeo-quercetina), flavonóide da classe dos flavonóis, é empregada como antioxidante, na prevenção ou tratamento da insuficiência venosa ou linfática e da fragilidade ou permeabilidade capilar (Bruneton, 1991; Velasco et al., 2008).

Autores como Arct e colaboradores (2002); Valenta, Nowack e Bernkop-Schnürch (1999); e Saija e colaboradores (1998) estudaram a penetração e permeação de flavonóides por metodologias in vitro em células de difusão.

Arct e colaboradores (2002) avaliaram a permeação da rutina, catequina e quercetina na presença de adjuvantes hidrofílicos (umectantes) e sua influência no perfil de permeação dos flavonóides através de uma membrana artificial. Segundo os resultados experimentais obtidos, estas substâncias atuaram como inibidores da permeação dos flavonóides em estudo, porém, em níveis diferentes de inibição.

Saija e colaboradores (1998) analisaram o perfil de liberação e permeação cutânea in vitro dos flavonóides quercetina, naringenina e hesperetina, utilizando a pele humana como modelo de membrana. Os pesquisadores estuda- ram a eficiência de dois promotores de permeação cutânea, o d-limoneno e a lecitina de soja. Os resultados indicaram que a quercetina não apresentou elevação de permeação com a adição dos promotores utilizados; o d-limoneno aumentou significativamente a permeação da naringenina e a lecitina de soja elevou a permeação da hesperetina.

Valenta, Nowack e Bernkop-Schnürch (1999) verificaram a permeação de rutina, como substância química modelo, veiculada na forma cosmética gel à base de deoxicolato de sódio, hidroxietilcelulose e polímero carboxivinílico. Os pesquisadores empregaram membrana artificial e pele de rato para a avaliação da permeação da rutina. Os resultados indicaram que o gel à base de deoxicolato de sódio favoreceu a permeação da rutina, atuando como veículo promotor. Os géis formulados com hidroxietilcelulose e polímero carboxivinílico não obtiveram resultados satisfatórios comparados com os obtidos com a preparação controle (solução aquosa de rutina).

A função barreira exercida pela pele promove dificuldades na penetração e permeação cutânea de componentes ativos cosméticos ou terapêuticos. Uma estratégia reconhecidamente efetiva para favorecer a passagem de substâncias através da pele é o emprego de promotores de penetração. Uma vasta gama de substâncias químicas foi avaliada para utilização como promotora de penetração cutânea, todavia, a incorporação em veículos cosméticos ou farmacêuticos é restrita devido à elucidação limitada de seus mecanismos de ação que se apresentam, comumente, complexos (Walker, Smith, 1996; Williams, Barry, 2004; Trommer, Neubert, 2006; Baby et al., 2008).

Em estudos de penetração através da pele, utilizando método de avaliação in vitro, a situação ideal seria utilizar pele humana como modelo, porém a pouca disponibilidade deste tipo de material, a necessidade de submeter o experimento ao Comitê de Ética e as dificuldades e custos de armazenamento e a viabilidade deste modelo de membrana tornam seu uso limitado (Schmook et al., 2001; Rigg, Barry, 1990).

Como alternativas de membranas, pesquisadores utilizam pele de animais de experimentação, membranas sintéticas e culturas tridimensionais, como a epiderme reconstruída, denominada pele equivalente. No Brasil, a pele de orelha de porco é um modelo de membrana amplamente utilizado devido à sua disponibilidade e, por ser um subproduto da indústria de alimentos (indústria da carne), apresenta relativa facilidade na sua obtenção. Segundo Haigh e Smith (1994) a pele de orelha de porco é similar ao tecido humano quanto à densidade de folículos pilosos.

Existe atualmente interesse no uso da muda de pele de cobra como modelos substitutos da pele humana e pesquisadores têm avaliado sua aplicabilidade em estudos 
de penetração/permeação com resposta favorável. Esta é composta de estrato córneo puro desprovido da epiderme viável e de folículos pilosos (Rigg, Barry, 1990). Fornece barreira similar ao estrato córneo humano e pode ser obtida abundantemente sem a morte do animal, uma vez que a troca de pele (ou ecdise) ocorre regularmente no animal adulto, em geral a cada 2 a 3 meses. A muda de pele de cobra apresenta armazenamento facilitado e não apresenta tendência à contaminação e degradação microbiológica, por não conter tecidos vivos (Itoh et al., 1990a; Itoh et al., 1990b; Widler, Sigrist, Gafner, 2002).

Mudas de pele de cobra possuem similaridades com o EC humano, como: espessura do tecido (EC humano - 13 a $15 \mu \mathrm{m}$; muda de pele de cobra - 10 a $20 \mu \mathrm{m})$; estrutura protéica (queratina do tipo $\alpha$ e $\beta$ ); composição lipídica (EC humano - 2,0 a 6,5\%; muda de pele de cobra - aproximadamente $6,0 \%$, envolvendo a presença de colesterol, ácidos graxos livres, glicoceramidas e fosfolipídeos, entre outros) (Widler, Sigrist, Gafner, 2002).

Nesta pesquisa, objetivos contemplados foram o desenvolvimento, a avaliação da estabilidade física, físico-química, química e funcional de uma emulsão cosmética contendo rutina e propilenoglicol, como promotor de penetração cutânea, e a avaliação da penetração e retenção cutânea in vitro do referido princípio ativo, empregando como modelo de biomembrana a muda de pele de cobra de Crotalus durissus.

\section{MATERIAL E MÉTODOS}

\section{Formulação}

O desenvolvimento da formulação envolveu a elaboração de uma emulsão, baseada em preparações desenvol- vidas previamente por Baby e colaboradores (2007a) contendo como substância ativa o flavonóide rutina e o propilenoglicol, como promotor de penetração cutânea, ambos a 5,0\% p/p. A composição quali/quantitativa ( $\% \mathrm{p} /$ p) está descrita na Tabela I.

\section{Avaliação Preliminar da Estabilidade}

A formulação foi submetida à Avaliação Preliminar da Estabilidade, empregando os Testes da Centrifugação e do Estresse Térmico.

\section{Teste da centrifugação}

Foram pesados cerca de 5,0 $\mathrm{g}$ da formulação em tubos de centrífuga. Procedeu-se ao Teste da Centrifugação, em réplicas de três, nas seguintes condições experimentais: temperatura ambiente $\left(25,0 \pm 2,0^{\circ} \mathrm{C}\right)$; velocidade de rotação de $3.000 \mathrm{rpm}(210 \mathrm{G})$; tempo de teste de 30 minutos.

\section{Teste do estresse térmico}

Cerca de 5,0 $\mathrm{g}$ da formulação foram pesados e transferidos para tubos de ensaio. As amostras, em réplicas de três, foram submetidas ao estresse térmico, em banhomaria termostatizado, no intervalo de temperatura controlada entre $40-80^{\circ} \mathrm{C}$, com progressão de elevação de $10{ }^{\circ} \mathrm{C} / 30$ minutos. As formulações foram avaliadas ao término de $80{ }^{\circ} \mathrm{C}$, após atingirem a temperatura ambiente $\left(25,0 \pm 2,0^{\circ} \mathrm{C}\right)$.

Após os Testes da Centrifugação e do Estresse Térmico, a formulação foi analisada macroscopicamente quanto ao aspecto (Idson, 1993; BRASIL, 2004).

TABELA I - Composição quali/quantitativa (\% p/p) das formulações.

\begin{tabular}{|c|c|c|c|}
\hline $\begin{array}{l}\text { Componentes } \\
\text { Nome químico }\end{array}$ & Nome INCI & Nome comercial & $\begin{array}{c}\text { Composição } \\
(\% \mathrm{p} / \mathrm{p})\end{array}$ \\
\hline $\begin{array}{l}\text { Álcool cetoestearílico (e) } \\
\text { fosfato de dicetila }(\mathrm{e}) \\
\text { fosfato cetílico }(10 \mathrm{OE})\end{array}$ & $\begin{array}{c}\text { Cetearyl alcohol (and) } \\
\text { dicetyl phosphate (and) } \\
\text { ceteth-10 phosphate }\end{array}$ & Crodafos ${ }^{\circledR}$ CES & 2,50 \\
\hline Adipato de diisopropila & Diisopropyl adipate & Ceraphyl ${ }^{\circledR} 230$ & 1,00 \\
\hline Miristato de isopropila & Isopropyl myristate & Crodamol $^{\circledR}$ IPM & 2,00 \\
\hline Butil hidroxitolueno & BHT & - & 0,10 \\
\hline $\mathrm{EDTA} \mathrm{Na}_{2}$ & Disodium EDTA & Uniquelan ${ }^{\circledR} \mathrm{NA} 2 \mathrm{~S}$ & 0,10 \\
\hline Goma xantana & Xanthan gum & Rhodicare ${ }^{\circledR} \mathrm{S}$ & 1,00 \\
\hline 2-Bromo-2-nitropropano-1,3-diol & 2-Bromo-2-nitropropane-1,3-diol & Protectol ${ }^{\circledR} \mathrm{BN}$ & 0,01 \\
\hline Água destilada & Aqua & - & 78,29 \\
\hline Propilenoglicol & Propylene glycol & - & 5,00 \\
\hline Polietilenoglicol 400 & PEG-8 & Carbowax $^{\circledR} 400$ & 5,00 \\
\hline Rutina PA & Rutin & Rutina & 5,00 \\
\hline
\end{tabular}




\section{Caracterização físico-química e física da formulação}

Valor de $\mathrm{pH}$

Foi determinado nas dispersões das amostras em água recém-destilada e na proporção 1:10 em réplicas de três e à temperatura ambiente $\left(25,0 \pm 2,0^{\circ} \mathrm{C}\right)$.

\section{Viscosidade aparente}

Foram pesados cerca de $10,0 \mathrm{~g}$ da formulação e transferidos para dispositivo destinado à análise de amostras com massa reduzida. As condições do viscosímetro ViscoStar (R) foram: agulha (spindle) TR 8 e velocidade de agitação de $10 \mathrm{rpm}$. $\mathrm{O}$ valor da viscosidade aparente $(\mathrm{cP})$ foi registrado após 1 minuto de agitação à temperatura ambiente de $25,0 \pm 2,0^{\circ} \mathrm{C}$.

\section{Validação da metodologia analítica para quantificação da rutina na formulação}

Empregou-se a espectrofotometria na região da radiação ultravioleta a $361,0 \mathrm{~nm}$ (espectrofotômetro Beckman DU - 640, com cubeta de quartzo com caminho óptico de $1 \mathrm{~cm}$ ), metodologia validada por Baby et al. (2006a) para a quantificação do flavonóide presente na emulsão. Como substância química de referência foi utilizada a rutina padrão secundário (pureza 96,1\%, NF XI, sem purificação prévia) e como solvente e branco de leitura espectrofotométrica a mistura de álcool etílico $95 \%$ e ácido acético 0,02 M na proporção de 99:1. O método espectrofotométrico foi validado quanto aos seguintes parâmetros: linearidade e estudo do intervalo; limites de detecção e quantificação; especificidade e pesquisa de interferentes; recuperação do padrão; precisão (intra e interdias) e exatidão (intra e interdias) (Causon, 1997; USP, 2003; Brasil, 2003; Rolim et al., 2005; Kassab et al., 2005; Maia et al., 2007).

\section{Penetração e retenção cutânea in vitro da rutina veiculada na formulação}

Preparo das células de difusão e padronização da muda de pele de Crotalus durissus

Mudas de pele de cobra de $C$. durissus íntegras foram gentilmente doadas pelo Instituto Butantã, que imediatamente após seu recebimento foram lavadas abundantemente com água destilada. O excesso de água foi removido com o emprego de papel toalha, aplicado com compressão suave. $\mathrm{O}$ processo de secagem foi finalizado à temperatura ambiente $\left(25,0 \pm 2,0^{\circ} \mathrm{C}\right)$. As mudas de pele foram armazenadas em bandejas de plástico, protegidas da luz e à temperatura ambiente $\left(25,0 \pm 2,0{ }^{\circ} \mathrm{C}\right)$ (Baby et al., 2006b; Baby et al., 2006c; Baby et al., 2007b).

Porções ventrais das mudas de pele de C. durissus, previamente à realização do estudo de penetração e retenção cutânea in vitro, foram padronizadas por remoção mecânica das camadas superficiais do tecido, aplicando fita adesiva uma vez (Transpore $\left.{ }^{\circledR}, 3 \mathrm{M}\right)$. Em seguida, foram hidratadas por imersão em água destilada, a $25,0 \pm 2,0{ }^{\circ} \mathrm{C}$ durante 24 horas, aproximadamente (Turunen et al., 1993; Megrab, Williams, Barry, 1995; Haigh et al., 1998; Pongjanyakul et al., 2002).

Mudas de pele de cobra de $C$. durissus foram recortadas e dispostas sobre seis células de difusão vertical (58001-455, Hanson Research), acopladas na plataforma para testes de tópicos e transdérmicos (Start Up 6 Cells, Variomag/Hanson Research), que foram preenchidas pela fase receptora composta pela solução de água destilada e álcool etílico absoluto 99,5\%, 1:1 (Saija et al., 1998; OECD, 2000; Reichling et al., 2006). Procedeu-as à agitação a 300 rpm por 10 minutos e, após este período, a fase receptora foi desprezada em sua totalidade e reposta completamente. O experimento foi conduzido a $37,0 \pm 0,5^{\circ} \mathrm{C}$ (Li, Birt, 1996; Haigh et al., 1998).

\section{Metodologia analítica para determinação da rutina após o estudo de penetração e retenção cutânea in vitro}

Curva analítica: linearidade e estudo do intervalo

A linearidade do método analítico para a determinação da rutina após a penetração e retenção cutânea in vitro foi avaliada por meio da curva analítica e tratamento estatístico dos dados, envolvendo diluições seriadas da rutina padrão de referência secundário, de pureza $96,1 \%$, sem purificação prévia, e da amostra comercial do referido componente ativo (Rutina PA, Tec Pharma/Henrifarma).

Foram preparadas soluções de concentrações: 0,5 ; 2,$0 ; 5,0 ; 10,0 ; 20,0$ e $30,0 \mu \mathrm{g} / \mathrm{mL}$, submetidas à leitura espectrofotométrica a $410,0 \mathrm{~nm}$, em réplicas de seis. Foi empregado como solvente e branco de leitura espectrofotométrica a mistura de água destilada, álcool etílico absoluto $99,5 \%$ e hidróxido de sódio $0,25 \mathrm{M}$, na proporção de 1:1:0,025 (Causon, 1997; Valenta, Nowack, Bernkop-Schnürch, 1999).

O cálculo da equação da reta da curva analítica foi realizado pela regressão linear por meio do método dos mínimos quadrados. Para cada concentração foram calculados a média das absorbâncias, o desvio padrão, a preci- 
são (como desvio padrão relativo) e a exatidão, obtendo-se o estudo do intervalo das concentrações da substância química de referência e a linearidade oferecida pelo método espectrofotométrico. O gráfico foi avaliado visualmente, verificando-se se houve relação linear de resposta, e pela análise estatística pertinente (ICH Q2B, 1995; BRASIL, 2003; Baby et al., 2006a).

\section{Especificidade}

A especificidade foi obtida comparando-se, por meio da sobreposição dos espectros de varredura da absorbância, em réplicas de dois e no intervalo de comprimento de onda entre 200,0 - 500,0 nm, soluções com concentração de $20,0 \mu \mathrm{g} / \mathrm{mL}$ do flavonóide rutina padrão de referência secundário e da amostra comercial do referido princípio ativo (Rolim et al., 2005). Utilizou-se como solvente e branco de leitura espectrofotométrica a mistura de água destilada, álcool etílico absoluto 99,5\% e hidróxido de sódio $0,25 \mathrm{M}$, na proporção de 1:1:0,025.

A obtenção da especificidade do método foi complementada por análise estatística sugerida por Feinberg e Raguènès (1999). Elaborou-se a curva das concentrações da amostra comercial da rutina em função das concentrações da substância química de referência, em réplicas de seis, nos valores 0,$5 ; 2,0 ; 5,0 ; 10,0 ; 20,0$ e $30,0 \mu \mathrm{g} / \mathrm{mL}$. As amostras foram submetidas à leitura espectrofotométrica a $410,0 \mathrm{~nm}$. Foram determinados o coeficiente angular e a intersecção com o eixo y por meio da obtenção da equação da reta.

A especificidade foi considerada adequada quando o coeficiente angular e a intersecção com o eixo y apresentaram valores estatisticamente iguais a, respectivamente, 1,0 e 0,0 (zero), empregando-se o Teste t de Student (Feinberg, Raguènès, 1999; Baby et al., 2006a).

Pesquisa de interferentes I: muda de pele de Crotalus durissus

Exatamente cerca de 50,0 mg de muda de pele de cobra de $C$. durissus padronizada foram pesados e transferidos para balão volumétrico de $50 \mathrm{~mL}$. Completou-se o volume com a solução de água destilada e álcool etílico absoluto $99,5 \%$ (1:1). Transferiu-se o conteúdo do balão volumétrico para vidraria adequada e iniciou-se agitação a $200 \mathrm{rpm}$, por 24 horas a $37,0 \pm 1,0{ }^{\circ} \mathrm{C}$. Após a temperatura da solução na presença da muda de pele de cobra atingir $25,0 \pm 2,0{ }^{\circ} \mathrm{C}$, procedeu-se à adição de $3,125 \mathrm{~mL}$ da solução de hidróxido de sódio $0,25 \mathrm{M}$. A solução foi reservada. Todo o procedimento foi realizado em réplicas de três.

A pesquisa de interferentes foi realizada por meio da sobreposição dos espectros de varredura da absorbância, em réplicas de dois e no intervalo de 200,0 - 500,0 nm, da rutina padrão de referência secundário, com concentração igual a $20,0 \mu \mathrm{g} / \mathrm{mL}$, e da solução hidroalcoólica obtida a partir da muda de pele de cobra $C$. durissus. Realizados os espectros de varredura da absorbância, estes foram analisados visualmente. O método analítico possuiu ausência de interferentes provenientes das mudas de pele de cobra de $C$. durissus quando estas não exibiram leitura espectrofotométrica a $410,0 \mathrm{~nm}$.

\section{Pesquisa de interferentes II: formulação}

Exatamente cerca de $300,0 \mathrm{mg}$ da formulação sem adição da rutina foram transferidos isoladamente para os compartimentos doadores das células de difusão vertical, empregando a muda de pele de cobra de Crotalus durissus padronizada. A distribuição das amostras nos compartimentos foi obtida com o auxílio de espátula plástica e flexível. Os experimentos foram conduzidos a $37,0 \pm 0,5^{\circ} \mathrm{C}$ e agitação constante de $300 \mathrm{rpm}$.

A pesquisa de interferentes envolvendo as formulações sem rutina em contato com as mudas de pele de cobra foi realizada durante seis horas. Em períodos de tempo prédeterminados, coletaram-se alíquotas de 1,0 mL das fases receptoras e adicionou-se $1,5 \mathrm{~mL}$ do solvente composto pela mistura de água destilada, álcool etílico absoluto $99,5 \%$ e hidróxido de sódio $0,25 \mathrm{M}(1: 1: 0,025)$, para a verificação de possíveis interferentes provenientes das preparações em contato com as biomembranas e o fluido receptor. As soluções foram submetidas à leitura espectrofotométrica a 410,0 $\mathrm{nm}$. O método foi considerado sem interferentes, nas condições experimentais descritas, se não ocorreu leitura espectrofotométrica no comprimento de onda citado anteriormente.

\section{Coeficiente de partição óleo/água}

O coeficiente de partição óleo/água do referido componente ativo foi determinado empregando-se $10,0 \mathrm{~mL}$ de miristato de isopropila (previamente saturado com água destilada) adicionado de $10,0 \mathrm{~mL}$ da solução da amostra comercial da rutina $(\approx 50,0 \mu \mathrm{g} / \mathrm{mL})$. A mistura foi submetida à agitação de $200 \mathrm{rpm}$, a $25,0 \pm 2,0^{\circ} \mathrm{C}$, por $30 \mathrm{minu}-$ tos (Hadgraft, Ridout, 1987). A mistura foi transferida para funil de separação e mantida em repouso por 10 minutos e separou-se a fase contendo a solução aquosa da rutina. Réplicas de três foram realizadas.

Antes e após a realização do coeficiente de partição óleo/água, alíquotas da fase aquosa foram adicionadas da mistura de água destilada, álcool etílico absoluto 99,5\% e hidróxido de sódio $0,25 \mathrm{M}(1: 1: 0,025)$ para quantificação 
da rutina. As soluções foram submetidas à leitura espectrofotométrica a 410,0 $\mathrm{nm}$.

\section{Coeficiente de partição estrato córneo de muda de pele de cobra Crotalus durissus/água}

Exatamente cerca de $30,0 \mathrm{mg}$ de muda de pele de cobra de $C$. durissus padronizada foram pesados e transferidos para $10 \mathrm{~mL}$ de solução aquosa da amostra comercial da rutina de $\approx 50,0 \mu \mathrm{g} / \mathrm{mL}$. A mistura foi submetida à agitação durante 30 minutos à temperatura ambiente $\left(25,0 \pm 2,0^{\circ} \mathrm{C}\right)$, a $200 \mathrm{rpm}$. Réplicas de três foram realizadas.

Alíquotas do sobrenadante foram tomadas e adicionadas da mistura de água destilada, álcool etílico absoluto $99,5 \%$ e hidróxido de sódio $0,25 \mathrm{M}, 1: 1: 0,025$ para quantificação de rutina. As soluções foram submetidas à leitura espectrofotométrica a $410,0 \mathrm{~nm}$.

Os coeficientes de partição óleo/água e estrato córneo de muda de pele de cobra de $C$. durissus/água foram expressos em valor logarítmico de base 10 (Rothwell, Day, Morgan, 2005).

\section{Penetração cutânea da rutina em muda de pele de Crotalus durissus}

Exatamente cerca de 300,0 mg da formulação foram transferidos isoladamente para os compartimentos doadores das células de difusão vertical de orifícios de $15 \mathrm{~mm}$ e área de exposição de $1,77 \mathrm{~cm}^{2}$. A distribuição das amostras nos compartimentos foi obtida com o auxílio de espátula plástica e flexível, a fim de garantir contato uniforme da formulação com a biomembrana.

O estudo da penetração cutânea in vitro da rutina presente na formulação foi realizado em réplicas de três, em muda de pele de cobra padronizada e por período de seis horas. Os compartimentos receptores foram preenchidos com solução de água destilada e álcool etílico absoluto $99,5 \%$ (1:1). Os experimentos foram conduzidos a $37,0 \pm$ $0,5^{\circ} \mathrm{C}$ com agitação constante de $300 \mathrm{rpm}$, exceto durante a coleta de alíquotas dos compartimentos receptores $(\mathrm{Li}$, Birt, 1996; Valenta, Nowack, Bernkop-Schnürch, 1999).

Foram tomadas manualmente alíquotas dos compartimentos receptores em períodos de tempo pré-definidos: 0,$00 ; 0,25 ; 0,50 ; 1,00 ; 1,50 ; 2,00 ; 3,00 ; 4,00 ; 4,50 ; 5,00$ e 6,00 horas. Concomitantemente às coletas, foi realizada a reposição nos compartimentos receptores com a solução de água destilada e álcool etílico absoluto 99,5\% (1:1) a $37,0 \pm 0,5^{\circ} \mathrm{C}$ para a manutenção do volume constante das células de difusão vertical de exatamente $7,0 \mathrm{~mL}$.

As alíquotas coletadas foram adicionadas do solvente composto pela mistura de água destilada, álcool etílico ab- soluto e hidróxido de sódio (1:1:0,025), para quantificação da rutina no fluido receptor. As soluções foram submetidas à leitura espectrofotométrica a 410,0 nm.

\section{Retenção cutânea in vitro}

As mudas de pele de cobra de $C$. durissus utilizadas na avaliação da penetração cutânea in vitro da rutina veiculada na formulação foram retiradas das células de difusão vertical após o término do experimento, recortadas adequadamente em concordância com a área de exposição $\left(1,77 \mathrm{~cm}^{2}\right)$ e em contato com a formulação.

O excesso da preparação foi removido das mudas de pele de cobra com auxílio de algodão embebido em água destilada e, posteriormente, em álcool etílico absoluto $99,5 \%$. As amostras foram reduzidas a fragmentos, pesadas e transferidas para balão volumétrico. Completou-se o volume com solvente, mistura de água destilada, álcool etílico absoluto 99,5\% e hidróxido de sódio $0,25 \mathrm{M}(1: 1: 0,025)$. Com o objetivo de favorecer a liberação da rutina retida no tecido para o solvente e branco de leitura, empregou-se o banho de ultra-som por 90 minutos. Alíquotas dos sobrenadantes foram tomadas e submetidas à leitura espectrofotométrica a 410,0 nm. Previamente à realização do experimento, determinou-se a recuperação do padrão retido no modelo de biomembrana.

\section{Testes de estabilidade acelerada}

Foram pesados cerca de $20,0 \mathrm{~g}$ da formulação e acondicionados em bisnagas opacas de polietileno, tampa de rosca do tipo flip-top, cor branca e capacidade de $30 \mathrm{~g}$ (amostras em réplicas de dois).

A formulação foi avaliada à temperatura ambiente de $25,0 \pm 2,0^{\circ} \mathrm{C}$ após o período de repouso de 48 horas do preparo (início do teste, dia 0 ou t t $_{0}$, a fim de se completar o processo de emulsificação. As condições de armazenamento e os dias pré-estabelecidos das análises estão descritos a seguir (Maia et al., 2006; Baby et al., 2007a):

1. $45,0 \pm 0,5^{\circ} \mathrm{C}$ durante 30 dias: análises no $5^{\circ}, 10^{\circ}, 15^{\circ}$, $20^{\circ}$ e $30^{\circ}$ dias;

2. Exposição à luz solar indireta e direta, à temperatura ambiente $\left(25,0 \pm 2,0^{\circ} \mathrm{C}\right)$, durante 30 dias: análises no $5^{\circ}$, $10^{\circ}, 15^{\circ}, 20^{\circ}$ e $30^{\circ}$ dias;

3. $5,0 \pm 0,5^{\circ} \mathrm{C}$ durante 30 dias: análises no $5^{\circ}, 10^{\circ}, 15^{\circ}, 20^{\circ}$ e $30^{\circ}$ dias.

As características físicas, físico-químicas, químicas e funcionais avaliadas nos dias pré-estabelecidos foram: valor de $\mathrm{pH}$; viscosidade aparente; teor da rutina remanescente na formulação e; penetração e retenção cutânea in vitro empregando como modelo de biomembrana a muda de pele de cobra de $C$. durissus padronizada. 


\section{RESULTADOS E DISCUSSÃO}

Devido à elevada e à crescente demanda dos produtos cosméticos, necessidades mercadológicas e dos consumidores, a promoção do envelhecimento precoce em sistemas emulsionados, por meio do armazenamento em condições drásticas de luminosidade, temperatura e umidade, permite reduzir o período exigido para a avaliação da estabilidade e, conseqüentemente, a predição do prazo de validade (Gil-Alegre et al., 2001).

Após a análise macroscópica da formulação submetida ao Teste da Centrifugação e ao Teste do Estresse Térmico, não foram identificados sinais de instabilidade, sendo assim, considerada adequada para os experimentos seguintes.

\section{Validação da metodologia analítica para quantificação da rutina na formulação}

A necessidade de se comprovar a qualidade das medições químicas, por meio da comparabilidade, rastreabilidade e confiabilidade têm exigido o desenvolvimento de novas metodologias analíticas que, após um processo denominado de validação, confere aos resultados determinados em laboratório, propiciarem informações confiáveis e interpretáveis sobre a amostra em estudo (Ribani et al., 2004). A Tabela II descreve os resultados da validação do método espectrofotométrico na região da radiação ultravioleta a $361,0 \mathrm{~nm}$ para a quantificação da rutina veiculada na formulação.

\section{Padronização da muda de pele de Crotalus durissus}

A utilização de muda de pele de cobra como modelo de biomembrana para ensaios de penetração cutânea exi- ge que este material seja hidratado previamente à sua utilização nas células de difusão, por se tratar de um tecido queratinoso não maleável e frágil, quando desidratado.

A estrutura da muda de pele de cobra possui três camadas distintas, a saber: (1) camada externa, denominada de $\beta$, composta por $\beta$-queratina; (2) camada intermediária ou meso, similar ao estrato córneo humano, possuindo de três a quatro estratos de células de espessura extremamente reduzida circundadas por lipídeos intercelulares e; (3) camada interna ou $\alpha$ composta por $\alpha$-queratina (Itoh et al., 1990a; Takahashi et al., 1993).

Itoh e colaboradores (1990a) e Takahashi e colaboradores (1993) identificaram que a camada intermediária ou meso apresenta-se como o obstáculo principal à permeabilidade de substâncias e, corroborando com as mesmas referências, Baby e colaboradores (2006b, 2006c e 2007b), que avaliaram a interação de tensoativos com muda de pele de cobra de Bothrops jararaca por técnicas espectrométricas (espectroscopia fotoacústica no infravermelho e Raman) e termoanalíticas (calorimetria exploratória diferencial), identificaram que somente após a remoção mecânica das camadas superficiais do tecido com fita adesiva houve a interação dos tensoativos dodecil sulfato de sódio, cloreto de hexadecil trimetil amônio e PEG-12 lauril éter com este material, evidenciando que, adicionalmente à camada meso, a camada $\beta$ contribui com o efeito barreira das mudas de pele de cobra, reduzindo a permeabilidade deste tecido às demais substâncias ativas em estudos de difusão. Pelo exposto, fez-se necessária a padronização da muda de pele de cobra de Crotalus durissus, como modelo de biomembrana, por meio da hidratação do tecido e remoção mecânica das camadas superficiais com fita adesiva.

TABELA II - Resultados da validação do método espectrofotométrico a 361,0 nm para a quantificação da rutina veiculada na formulação (solvente e branco: álcool etílico 95\% e ácido acético 0,02 M, 99:1)

\begin{tabular}{lc}
\hline Parâmetros & Resultados experimentais \\
\hline Linearidade & 5,0 a $40,0 \mu \mathrm{g} / \mathrm{mL}$ \\
Equação da reta & $\mathrm{y}=0,0301( \pm 0,00012) \mathrm{x}-0,0219( \pm 0,00164)$ \\
Coeficiente de correlação linear & $0,9992 \pm 0,00012$ \\
Especificidade & Específico para a rutina e ausente de interferentes \\
Limite de detecção & $0,146 \mu \mathrm{g} / \mathrm{mL}$ \\
Limite de quantificação & $0,442 \mu \mathrm{g} / \mathrm{mL}$ \\
Recuperação do padrão & $112,690 \pm 2,809 \%$ \\
Precisão intradia & 4,33 a $5,57 \%$ \\
Precisão interdias & 3,06 a $4,68 \%$ \\
Exatidão intradia & $109,06 \pm 4,72$ a $114,30 \pm 6,36 \%$ \\
Exatidão interdias & $111,40 \pm 3,41$ a $115,53 \pm 4,59 \%$ \\
\hline
\end{tabular}

$x$ : concentração do flavonóide rutina padrão de referência secundário $(\mu \mathrm{g} / \mathrm{mL}) ; y$ : absorbância. 


\section{Metodologia analítica para determinação da rutina após penetração e retenção cutânea in vitro}

O método analítico proporcionou linearidade de resposta da absorbância em função da concentração para as soluções da rutina padrão de referência secundário e da amostra comercial do referido composto ativo, na mistura de água destilada, álcool etílico absoluto 99,5\% e hidróxido de sódio $0,25 \mathrm{M}(1: 1: 0,025)$, no intervalo de concentrações entre 0,5 e $30,0 \mu \mathrm{g} / \mathrm{mL}$, submetidas à leitura espectrofotométrica a $410,0 \mathrm{~nm}$.

Na Figura 1 estão representados os resultados experimentais da curva analítica da substância química de referência e da amostra comercial da rutina, respectivamente.

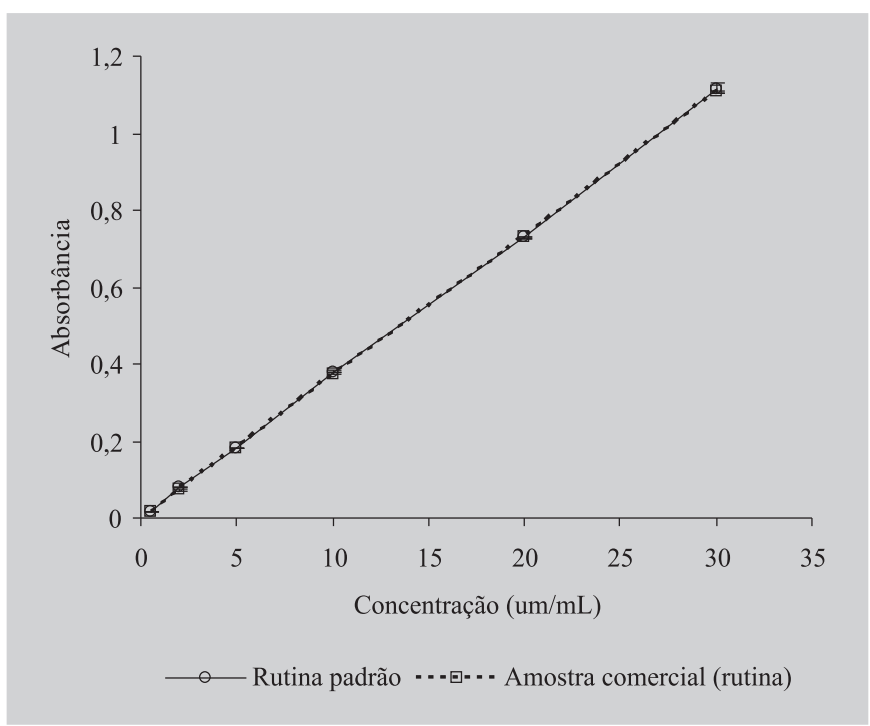

FIGURA 1 - Curvas padrão da rutina padrão de referência secundário $(\mathrm{T}=96,1 \%)$ e da amostra comercial do referido componente ativo $(\mathrm{n}=6) . \lambda=410,0 \mathrm{~nm}$. Solvente e branco: água destilada, álcool etílico $99,5 \%$ e solução de hidróxido de sódio $0,25 \mathrm{M}(1: 1: 0,025)$.

O cálculo da regressão linear, pelo método dos mínimos quadrados, gerou a equação da reta descrita a seguir
(Equação 1), e coeficiente de correlação linear $\left(\mathrm{R}^{2}\right)$ igual a $0,9996 \pm 0,00014$.

$$
\mathbf{y}=0,0374( \pm 0,00113) \mathbf{x}+0,0012( \pm 0,00156)
$$

EQUAÇÃO 1 - Equação da reta obtida pelo método dos mínimos quadrados. $x$ é a concentração da rutina padrão de referência secundário $(\mu \mathrm{g} / \mathrm{mL})$; $y$ é a absorbância.

Valores entre parênteses descrevem o desvio padrão.

A Tabela III descreve os resultados do tratamento estatístico (ANOVA) aplicado às informações obtidas experimentalmente para a elaboração da curva analítica.

$\mathrm{O}$ valor de F calculado $(11.916,04)$ foi superior ao valor de $\mathrm{F}_{\text {crítico }}$ o que evidenciou a significância estatística do cálculo da regressão linear pelo método dos mínimos quadrados para comprovação da relação linear das medidas das absorbâncias em função das concentrações da substância química de referência (Feinberg \& Raguenes, 1999).

O estudo do intervalo (Tabela IV) confirmou a adequação dos valores das concentrações da substância química de referência empregados na construção da curva analítica pelos cálculos da precisão (DPR, \%) e exatidão.

Os valores da exatidão ( \pm desvio padrão) localizaram-se no intervalo entre $84,288 \pm 2,320$ e $106,345 \pm$ $0,779 \%$ e os da precisão entre 0,371 e $2,753 \%$, próximos dos valores de concentração aceitos como reais e dispersão reduzida dos resultados experimentais, respectivamente.

Como também apresentado na Tabela IV, o estudo do intervalo para as diluições da amostra comercial da rutina proporcionou a obtenção de valores no intervalo de 0,186 a 3,067\% e de $93,948 \pm 2,882$ a $101,924 \pm 0,350 \%$ para a precisão (DPR, \%) e exatidão, respectivamente, considerados adequados para a validação da metodologia analítica (Jenke, 1996).

A análise espectrofotométrica da rutina padrão de referência secundário, na mistura da água destilada, álcool etílico absoluto $99,5 \%$ e hidróxido de sódio $0,25 \mathrm{M}$ (1:1:0,025), obteve um pico de absorbância máxima a

TABELA III - Tratamento estatístico (ANOVA) aplicado para a construção da curva analítica da rutina padrão de referência secundário $(\mathrm{T}=96,1 \%)$ para $\alpha=5 \%(\lambda: 410,0 \mathrm{~nm})$

\begin{tabular}{lccccc}
\hline & GL & SQ & MQ & F & F $_{\text {critico }}$ \\
\hline Regressão & 1 & 0,91679 & 0,91679 & $11.916,04$ & $4,22 \times 10^{-8}$ \\
Residuo & 3 & $3,08 \times 10^{-4}$ & $7,69 \times 10^{-5}$ & & \\
Total & 4 & 0,91098 & & & \\
\hline
\end{tabular}

$G L$ : graus de liberdade; $S Q$ : soma dos mínimos quadrados; $M Q$ : médias dos mínimos quadrados; $F$ : valor de ANOVA-F calculado; $F_{\text {critico }}$ : valor de ANOVA-F tabelado (Gil-Alegre et al., 2001). 
410,0 nm. De acordo com Valenta, Nowack e BernkopSchnürch (1999) o pico de absorbância máxima para a rutina ocorre no comprimento de onda de $405 \mathrm{~nm}$, mas em função do equipamento utilizado, grau de pureza dos solventes e da substância química de referência ou dos erros de metodologia analítica podem ocorrer variações do resultado experimental e o apresentado na literatura científica.

A relação linear de resposta entre as concentrações da amostra comercial da rutina em função das concentrações do flavonóide padrão de referência secundário, para a determinação da especificidade, está representada na Figura 2 e Tabela V.

A proporcionalidade foi confirmada pela obtenção da

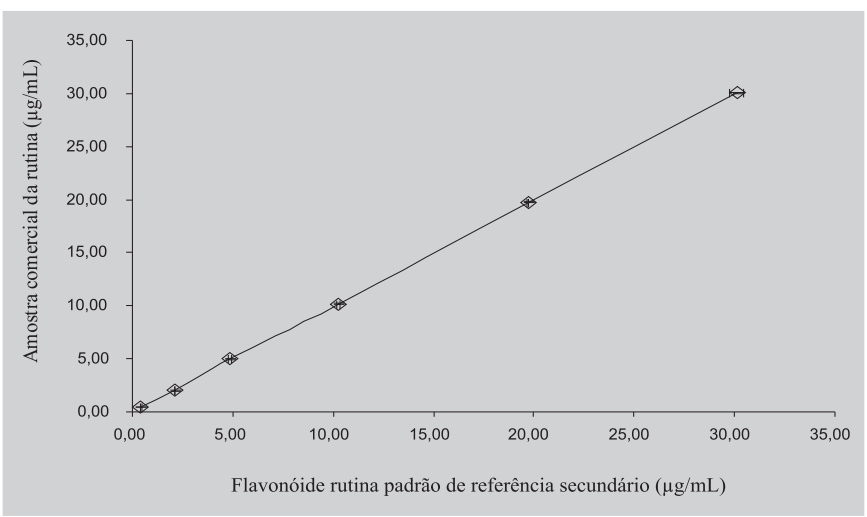

FIGURA 2 - Relação entre as concentrações da amostra comercial da rutina e substância química de referência ( $\mathrm{T}$ $=96,1 \%$ ) para determinação da especificidade do método espectrofotométrico a 410,0 nm $(\mathrm{n}=6)$. A mistura de água destilada, álcool etílico 99,5\% e solução de hidróxido de sódio $0,25 \mathrm{M}(1: 1: 0,025)$ foi empregada como solvente e branco de leitura. equação da reta (Equação 2), do tratamento estatístico (Tabela VI) e do valor do coeficiente de correlação linear.

$$
\begin{gathered}
\mathbf{y}=0,9994( \pm 0,0110) \mathbf{x}+0,0016( \pm 0,0425), \\
\mathbf{R}^{2}=0,9999 \pm 0,000098
\end{gathered}
$$

EQUAÇÃO 2 - Equação da reta obtida para determinação da especificidade do método espectrofotométrico na quantificação da rutina a $410,0 \mathrm{~nm}$. Na qual: $x$ é a concentração da rutina padrão de referência secundário $(\mu \mathrm{g} / \mathrm{mL})$;

$y$ é a concentração da amostra comercial do referido

composto ativo; $R^{2}$ é o coeficiente de correlação linear.

A Tabela VI expõe o resultado do tratamento estatístico empregado para a avaliação da avaliação da especificidade do método espectrofotométrico a $410,0 \mathrm{~nm}$ para a amostra comercial da rutina.

Em concordância com os resultados obtidos, o método foi considerado específico para a determinação da rutina ( $\lambda=410,0 \mathrm{~nm}$; branco e solvente espectrofotométrico: água destilada, álcool etílico 99,5\% e solução de hidróxido de sódio $0,25 \mathrm{M}, 1: 1: 0,025)$, pois os valores do coeficiente angular e da intersecção com o eixo y não apresentaram diferença estatística dos valores críticos 1,00 e 0,00 (zero), respectivamente, e valor de $\mathrm{R}^{2}$ igual a $0,9999 \pm 0,000098$, próximo a 1 (Feinberg, Raguènès, 1999).

O método espectrofotométrico foi considerado ausente de interferentes provenientes da solução hidroalcoólica obtida a partir da muda de pele de cobra de Crotalus durissus e dos fluidos receptores das formulações sem rutina em contato com as mudas de pele de cobra dispostas nas células de difusão por um período de seis horas.

A adição do hidróxido de sódio 0,25 M no solvente do

TABELA IV - Estudo do intervalo das concentrações da rutina padrão de referência secundário e da amostra comercial da rutina $(\lambda=410,0 \mathrm{~nm})$.

\begin{tabular}{lcccccc}
\hline CT & & Rutina padrão & & Amostra comercial \\
& $\mathrm{C}_{\text {média }+\mathrm{dp}}$ & $\mathrm{E} \mathrm{( \% )}$ & DPR (\%) & $\mathrm{C}_{\text {média }+\mathrm{dp}}$ & $\mathrm{E}(\%)$ & $\mathrm{DPR}(\%)$ \\
\hline $\mathbf{0 , 5}$ & $0,421 \pm 0,012$ & $84,288 \pm 2,320$ & 2,753 & $0,470 \pm 0,014$ & $93,948 \pm 2,882$ & 3,067 \\
$\mathbf{2 , 0}$ & $2,127 \pm 0,016$ & $106,345 \pm 0,779$ & 0,733 & $1,999 \pm 0,013$ & $99,932 \pm 0,646$ & 0,646 \\
$\mathbf{5 , 0}$ & $4,856 \pm 0,052$ & $97,128 \pm 1,036$ & 1,067 & $4,964 \pm 0,020$ & $99,277 \pm 0,408$ & 0,411 \\
$\mathbf{1 0 , 0}$ & $10,272 \pm 0,069$ & $102,718 \pm 0,685$ & 0,667 & $10,192 \pm 0,035$ & $101,924 \pm 0,350$ & 0,343 \\
$\mathbf{2 0 , 0}$ & $19,696 \pm 0,073$ & $98,479 \pm 0,365$ & 0,371 & $19,773 \pm 0,046$ & $98,866 \pm 0,231$ & 0,233 \\
$\mathbf{3 0 , 0}$ & $30,125 \pm 0,355$ & $100,415 \pm 1,183$ & 1,178 & $30,065 \pm 0,056$ & $100,218 \pm 0,186$ & 0,186 \\
\hline
\end{tabular}

$C T$ : concentrações teóricas da rutina padrão secundário de referência e de sua amostra comercial $(\mu \mathrm{g} / \mathrm{mL}) ; C_{\text {média }+d p}:$ média \pm desvio padrão das concentrações calculadas da rutina $(\mu \mathrm{g} / \mathrm{mL}), \mathrm{n}=6 ; E(\%)$ : exatidão $(\%) ; D P R(\%)$ : precisão calculada como desvio padrão relativo (\%). As concentrações calculadas da rutina $(\mu \mathrm{g} / \mathrm{mL})$ foram obtidas empregando-se a equação $\mathrm{y}=0,0374( \pm 0,00113) \mathrm{x}+0,0012( \pm 0,00156)$. 
TABELA V - Concentrações da amostra comercial da rutina em função da substância química de referência para determinação da especificidade do método espectrofotométrico a 410,0 nm.

\begin{tabular}{lcc}
\hline Concentração nominal da substância química de referência $(\mu \mathrm{g} / \mathrm{mL})$ & $\mathrm{C}_{\mathrm{SQR} \pm \mathrm{dp}}$ & $\mathrm{C}_{\mathrm{A} \pm \mathrm{dp}}$ \\
\hline $\mathbf{0 , 5}$ & $0,42 \pm 0,012$ & $0,47 \pm 0,014$ \\
$\mathbf{2 , 0}$ & $2,13 \pm 0,016$ & $2,00 \pm 0,013$ \\
$\mathbf{5 , 0}$ & $4,86 \pm 0,052$ & $4,96 \pm 0,020$ \\
$\mathbf{1 0 , 0}$ & $10,27 \pm 0,069$ & $10,19 \pm 0,035$ \\
$\mathbf{2 0 , 0}$ & $19,70 \pm 0,073$ & $19,77 \pm 0,046$ \\
$\mathbf{3 0 , 0}$ & $30,13 \pm 0,355$ & $30,07 \pm 0,056$ \\
\hline
\end{tabular}

$C_{S Q R \pm d p}:$ média das concentrações e desvio padrão $(\mathrm{n}=6)$ da rutina padrão de referência secundário $(\mu \mathrm{g} / \mathrm{mL}) ; C_{A \pm d p}:$ média das concentrações e desvio padrão $(n=6)$ da amostra comercial da rutina. As concentrações foram calculadas utilizandose a equação $\mathrm{y}=0,0374( \pm 0,00113) \mathrm{x}+0,0012( \pm 0,00156)$.

TABELA VI - Especificidade do método espectrofotométrico a 410,0 nm. Cálculo segundo Feinberg e Raguènès (1999) para a rutina, com nível de significância de $\alpha=5 \%$.

\begin{tabular}{lcc}
\hline Tratamento Estatístico & $\mathrm{V}_{\mathrm{D}}$ & $\mathrm{V}_{\mathrm{C}}$ \\
\hline $\begin{array}{l}\text { Coeficiente angular } \\
\text { Desvio padrão do }\end{array}$ & 0,9994 & 1,0 \\
coeficiente angular & 0,0110 & - \\
$\begin{array}{l}\text { Intersecção com o eixo y } \\
\text { Desvio padrão da }\end{array}$ & 0,0016 & 0,0 \\
intersecção com o eixo y & 0,0425 & - \\
Graus de liberdade & & \\
Teste t de Student para CA & 0,8992 & 2,2281 * \\
Teste t de Student para I-y & 0,9283 & \\
\hline
\end{tabular}

$V_{D}:$ valores determinados; $V_{C}:$ valores críticos; $C A$ : coeficiente angular; $I-y$ : intersecção com o eixo y; *: t de Student tabelado.

método a 410,0 nm favoreceu a eliminação dos possíveis interferentes da quantificação da rutina. Tal constatação foi observada por meio do efeito batocrômico (Valenta, Nowack, Bernkop-Schnürch, 1999), com deslocamento do pico de máxima absorbância da referida substância ativa para a região da radiação visível.

O presente trabalho necessitou o desenvolvimento e a validação de dois métodos espectrofotométricos para a quantificação da rutina devido às exigências experimentais. O método a $361,0 \mathrm{~nm}$ foi empregado para a quantificação da rutina nas emulsões cosméticas, especificamente para o estudo da estabilidade (Testes de Estabilidade Acelerada) e, o método a 410,0 nm, para a determinação da rutina retida no modelo de biomembrana alternativo e penetrada através deste, por meio do estudo de difusão.

\section{Coeficientes de partição óleo/água e estrato de córneo de muda de pele de Crotalus durissus/água}

A obtenção dos valores logarítmicos dos coeficientes de partição se tornou um procedimento padrão para a predição do transporte (difusão) em membranas ou da tendência de interação/associação de substâncias ativas. Segundo Florence eAttwood (1988), Rothwell, Day e Morgan (2005) propriedades como hidrofilia ou lipofilia (in vivo) de componentes ativos orientam a tendência da interação destes com os sistemas biológicos, que envolvem membranas ou proteínas. A lipofilia de substâncias ativas, como por exemplo, aquelas submetidas aos ensaios de difusão, pode ser expressa como coeficiente de partição, uma constante de equilíbrio que correlaciona o modo no qual um soluto partilha entre ambientes apolares e polares (Hadgraft, Ridout, 1987; Rothwell, Day, Morgan, 2005).

Os valores logarítmicos de base 10 dos coeficientes de partição óleo/água e estrato córneo de muda de pele de cobra de $C$. durissus/água foram - 0,697 e - 1,239, respectivamente. Segundo Zatz (1993) admitindo-se que a pele de muda de cobra de C. durissus se comporte como modelo de biomembrana composta por domínios lipídicos e porosos dispostos paralelamente ou intercalados, somente difusantes possuindo valores logarítmicos de coeficientes de partição óleo/água reconhecidos como moderado a elevado (acima de zero) possuem tendência favorável para a penetração através da membrana.

Corroborando com o resultado obtido experimentalmente, Rothwell, Day e Morgan (2005) obtiveram o valor de - 0,64 de coeficiente de partição óleo/água para a rutina.

\section{Penetração cutânea da rutina}

A avaliação da penetração cutânea da rutina veiculada na emulsão contendo propilenoglicol 5,0\% p/p, como 
promotor de penetração cutânea, possuiu como modelo de biomembrana a muda de pele de $C$. durissus. Embora a muda de pele de cobra não seja um tegumento de procedência de mamíferos, este material biológico apresenta similaridade ao estrato córneo humano e vantagens potenciais que a tornam um modelo de membrana para ensaios de difusão.

A emulsão não apresentou tendência para favorecer o transporte da substância ativa para a fase receptora, mesmo com método espectrofotométrico a $410,0 \mathrm{~nm}$ ter gerado valor de limite de quantificação estimado para a rutina igual a $0,308 \mu \mathrm{g} / \mathrm{mL}$. Conseqüentemente, não foi verificada penetração cutânea da rutina através da pele de muda de $C$. durissus no período de seis horas, comportamento corroborado com o valor logarítmico do coeficiente de partição óleo/água reduzido de - 0,697 (Florence, Attwood, 1988) e com estudos realizados por Li e Birt (1996) e Casagrande e colaboradores (2007) que observaram a tendência dos flavonóides em não penetrar membranas biológicas em ensaios de difusão, utilizando, respectivamente, como modelos a pele humana e a pele de porco.

Opostamente às referências anteriormente citadas, Valenta, Nowack e Bernkop-Schnürch (1999) verificaram a penetração da rutina através da pele de rato e, adicionalmente, sugeriram que o referido composto ativo tende a interagir com o modelo de membrana utilizado, comportamento também verificado nesta pesquisa com a rutina em relação a muda de pele de cobra.

Montenegro e colaboradores (2007) estudaram a penetração cutânea da quercetina e seus ésteres de 3-oacila através da pele humana. Os autores constataram a penetração cutânea da quercetina e, adicionalmente, os mesmos identificaram que o período de tempo de realização do experimento foi um fator de extrema relevância. Segundo a mesma referência, o período de tempo para o ensaio de difusão deve ser igual ou superior a 22 horas, pois somente a partir deste intervalo de tempo houve a identificação e quantificação da quercetina no fluido receptor das células de difusão utilizadas pelos autores e, conseqüentemente, possibilitou o cálculo do valor de fluxo para o flavonóide através da pele humana, empregada como membrana modelo.

A fim de se verificar se o tempo de realização do experimento desta pesquisa não se apresentava apropriado, outro ensaio de difusão foi conduzido nas mesmas condições experimentais, exceto para a duração do experimento, que foi modificada para 52 horas e, novamente, houve a tendência do não favorecimento do transporte da rutina através do modelo de membrana e, por conseguinte, não se verificou a penetração cutânea da rutina através da muda de pele de cobra.

\section{Retenção cutânea in vitro}

As mudas de pele de $C$. durissus utilizadas na avaliação da penetração cutânea in vitro da rutina foram retiradas das células de difusão vertical, após o período de seis horas de experimento, e avaliadas quanto a tendência em reter a referida substância ativa.

Após a quantificação da rutina retida no modelo de biomembrana ( $\mu \mathrm{g}$ de rutina/mg de muda de pele de cobra), obteve-se valor igual a $0,931 \pm 0,0391 \mu \mathrm{g} / \mathrm{mg}$ (o método apresentou valor de recuperação do padrão igual a 87,126 $\pm 1,018 \%$ ).

\section{Testes de Estabilidade Acelerada}

Os estudos de estabilidade de produtos cosméticos e farmacêuticos procuram fornecer informações que indiquem o grau de estabilidade relativa de um produto nas condições diversas de exposição a que possa estar sujeito, até o encerramento de seu prazo de validade (Brasil, 2004). Geram subsídios para a orientação nos estudos de desenvolvimento, como: na escolha dos componentes da formulação e do material de acondicionamento adequado; forma de apresentação; materiais de acondicionamento e embalagens alternativos e; confirmação do prazo de validade estimado.

As informações obtidas no estudo de estabilidade são particularmente importantes para os veículos emulsionados, pois quando estocados podem fornecer sinais de desestabilização como: cremeação, sedimentação, floculação, coalescência e, por fim, separação das fases e a inativação de substâncias ativas e ineficácia do sistema (Idson, 1993).

Os Testes de Estabilidade Acelerada visaram conferir à formulação condições para o envelhecimento acelerado, permitindo avaliar o perfil de estabilidade física, físico-química, química e funcional, segundo os parâmetros avaliados. Trata-se, portanto, de um teste orientativo, indicando qual veículo cosmético em estudo confere estabilidade adequada.

A Tabela VII ilustra os resultados dos parâmetros físicos, físico-químicos e químicos (teor remanescente da concentração da rutina) para a formulação.

Os valores de pH (Tabela VII) resultaram em redução com variações de maior intensidade aparente na condição de estufa a $45,0 \pm 0,5^{\circ} \mathrm{C}$, com intervalo percentual de variação entre zero e - 16,67\%. Apesar das alterações, os valores de $\mathrm{pH}$ mantiveram-se compatíveis com o valor de $\mathrm{pH}$ fisiológico $(6,0$ a 7,2). Na temperatura elevada da condição de armazenamento a $45,0 \pm 0,5^{\circ} \mathrm{C}$, alterações significativas eram esperadas para este parâmetro físico-químico analisa- 
do, pois a elevação da temperatura possui influência direta na estabilidade física, físico-química e química de diversas formas cosméticas e dos princípios ativos (Baby et al., $2007 \mathrm{a})$. As condições de ambiente $\left(25,0 \pm 2,0^{\circ} \mathrm{C}\right)$ e refrigerador $\left(5,0 \pm 0,5^{\circ} \mathrm{C}\right)$ se apresentaram adequadas como condição de armazenamento para a emulsão, possuindo tendência inferior de variações percentuais entre - 1,39 a - 8,33\% e zero a $-6,94 \%$, respectivamente.

As alterações percentuais do valor de $\mathrm{pH}$, verificadas nesta pesquisa, é corroborada com os resultados obtidos por Baby e colaboradores (2007a) para uma emulsão cosmética fluida de composição similar contendo, como substância ativa, 5,0\% p/p do extrato de Trichilia catigua Adr. Juss (e) Ptychopetalum olacoides Bentham, padronizado em flavonóides totais, expressos em rutina. Segundo os mesmos autores, foram observadas variações percentuais mais relevantes do valor deste parâmetro físico-químico na condição de armazenamento de refrigerador $\left(5,0+0,5^{\circ} \mathrm{C}\right)$ e estufa $\left(40,0 \pm 0,5^{\circ} \mathrm{C}\right)$. As formulações citadas anteriormente foram armazenadas em um período de 90 dias.

Os valores da viscosidade aparente (Tabela VII), em todas as condições de armazenamento, acarretaram em variações percentuais diminutas entre - 0,4 (3.440 cP) a $9,2 \%$ (3.770 cP) em relação ao valor da viscosidade aparente obtida após 48 horas de repouso $\left(\mathrm{t}_{0}\right)$, igual a $3.453 \mathrm{cP}$.

A estabilidade química determinada em função do teor remanescente da rutina (\%) (Tabela VII) foi avaliada por meio da quantificação do referido componente ativo pelo método espectrofotométrico na região do ultravioleta a 361,0 $\mathrm{nm}$ previamente validado (Baby et al., 2006a).

Nas condições de armazenamento em temperatura ambiente $\left(25,0 \pm 2,0{ }^{\circ} \mathrm{C}\right)$, em refrigerador $\left(5,0 \pm 0,5^{\circ} \mathrm{C}\right) \mathrm{e}$ em estufa $\left(45,0 \pm 0,5^{\circ} \mathrm{C}\right)$, a emulsão se apresentou quimicamente estável, durante 30 dias. Embora temperaturas elevadas favoreçam a deterioração dos flavonóides por serem compostos polifenólicos sensíveis à presença de metais, à radiação ultravioleta, à temperatura e à hidrólise (Friedman, Jürgens, 2000), não foi verificado tendência à degradação da rutina armazenada a $45,0 \pm 0,5^{\circ} \mathrm{C}$ (em um período de, pelo menos, 30 dias), mesmo com a constatação da variação do valor de $\mathrm{pH}$, indicando que a modificação deste parâmetro físico-químico, no intervalo percentual de zero e $-16,67 \%$, não causou elevação da degradação da substância ativa.

Estudos de retenção cutânea in vitro foram realizados durante os Testes de Estabilidade Acelerada para formulação armazenado unicamente na condição de temperatura ambiente, a $25,0 \pm 2,0^{\circ} \mathrm{C}$, e nos dias zero $\left(\mathrm{t}_{0}\right), 20$ e 30 . Os valores da retenção cutânea da rutina na muda de pele de cobra de $C$. durissus foram iguais a $0,931 \pm 0,0391\left(\mathrm{t}_{0}\right)$; $1,754 \pm 0,442$ (dia 20) e 0,468 $\pm 0,0618 \mu \mathrm{g} / \mathrm{mg}$ (dia 30).

Constatou-se que, no período de realização dos Testes de Estabilidade Acelerada, emulsão se manteve adequada quanto ao favorecimento da retenção da referida substância ativa no estrato córneo do modelo de biomembrana utilizado e, novamente, não houve penetração cutânea da rutina através da muda de $C$. durissus.

\section{CONCLUSÕES}

A emulsão cosmética contendo rutina e propilenoglicol, como promotor de penetração cutânea, ambos a 5,0\% p/p foi considerada estável após a Avaliação Preliminar da Estabilidade em todas as condições de armazenamento $\left(25,0 \pm 2,0{ }^{\circ} \mathrm{C}\right.$; $5,0 \pm 0,5^{\circ} \mathrm{C}$ e $45,0 \pm 0,5^{\circ} \mathrm{C}$ ), em um período de 30 dias. Os métodos espectrofotométricos a $361,0 \mathrm{~nm}$ e a $410,0 \mathrm{~nm}$ foram padronizados e validados quanto aos critérios: linearidade, especificidade, ausência de interferentes, limites de detecção e de quantificação reduzidos, recuperação do padrão, precisão e exatidão adequados.

TABELA VII - Avaliação dos parâmetros físicos, físico-químicos e químicos (teor remanescente da concentração da rutina) da emulsão submetida aos Testes de Estabilidade Acelerada.

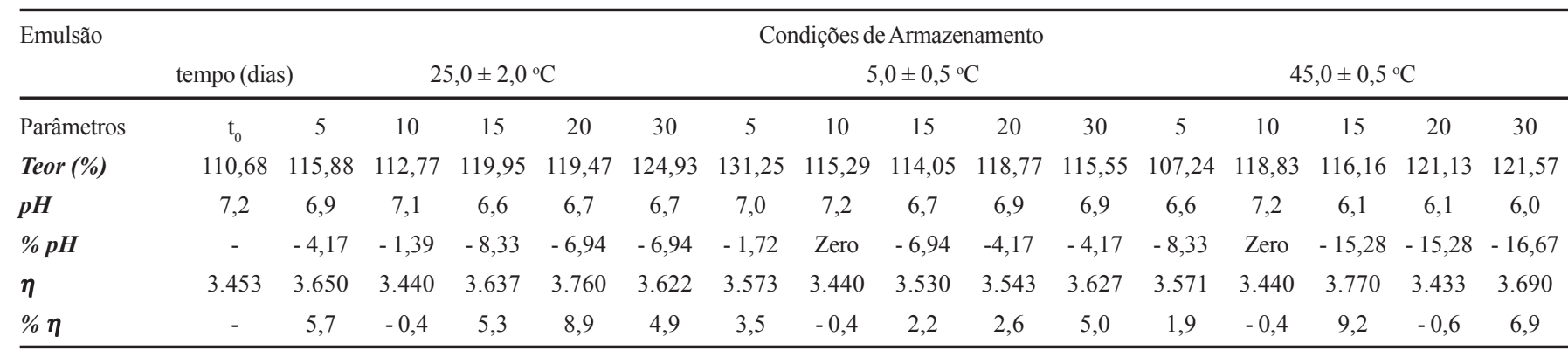

(-): não avaliado; $\eta$ : viscosidade aparente (em cP); $t_{0}$ : tempo de repouso (48 horas após o preparo); \% $p H$ : variação percentual do valor de $\mathrm{pH}$ em relação ao $\mathrm{pH}$ inicial; $\%$ $\eta$ : variação percentual do valor da viscosidade aparente em relação à viscosidade aparente inicial; Teor (\%): concentração percentual da rutina remanescente na formulação. 
O estudo da penetração cutânea in vitro da rutina na emulsão cosmética, utilizando a muda de pele de cobra de Crotalus durissus como modelo de biomembrana alternativo, evidenciou o não favorecimento da passagem da substância ativa para a fase receptora através do estrato córneo de $C$. durissus, porém, foi verificada a retenção cutânea da rutina no modelo de biomembrana.

\section{ABSTRACT \\ Stability and in vitro penetration study of rutin incorporated in a cosmetic emulsion through an alternative model biomembrane}

Rutin is employed as antioxidant and to prevent the capillary fragility and, when incorporated in cosmetic emulsions, it must target the action site. In vitro cutaneous penetration studies through human skin is the ideal situation, however, there are difficulties to obtain and to maintain this tissue viability. Among the membrane models, shed snake skin presents itself as pure stratum corneum, providing barrier function similar to human and it is obtained without the animal sacrifice. The objectives of this research were the development and stability evaluation of a cosmetic emulsion containing rutin and propylene glycol (penetration enhancer) and the evaluation of rutin in vitro cutaneous penetration and retention from the emulsion, employing an alternative model biomembrane. Emulsion was developed with rutin and propylene glycol, both at $5.0 \% \mathrm{w} / \mathrm{w}$. Active substance presented on the formulation was quantified by a validated spectrophotometric method at $361.0 \mathrm{~nm}$. Rutin cutaneous penetration and retention was performed in vertical diffusion cells with shed snake skin of Crotalus durissus, as alternative model biomembrane, and distilled water and ethanol $99.5 \%$ (1:1), as receptor fluid. The experiment was conducted for six hours, at $37.0 \pm 0.5^{\circ} \mathrm{C}$ with constant stirring of $300 \mathrm{rpm}$. Spectrophotometry at $410.0 \mathrm{~nm}$, previously validated, determined the active substance after cutaneous penetration/ retention. Emulsion did not promote rutin cutaneous penetration through $\mathrm{C}$. durissus skin, retaining $0.931 \pm$ $0.0391 \mu \mathrm{g}$ rutin $/ \mathrm{mg}$ shed snake skin. The referred formulation was chemically stable for 30 days after stored at $25.0 \pm 2.0$ ${ }^{\circ} \mathrm{C}, 5.0 \pm 0.5^{\circ} \mathrm{C}$ and $45.0 \pm 0.5^{\circ} \mathrm{C}$. In conclusion, it has not been verified the active cutaneous penetration through the model biomembrane, but only its retention on the Crotalus durissus stratum corneum, condition considered stable for 30 days.

UNITERMS: Accelerated stability test. Emulsion. Propylene glycol. Shed snake skin. Cutaneous penetration/in vitro study. Rutin.

\section{AGRADECIMENTOS}

Os autores gostariam de agradecer à CAPES, ao $\mathrm{CNPq} / \mathrm{MCT}$, ao Instituto Butantã, em especial ao Dr. Wilson Fernandes e ao Dr. Otávio Azevedo Mercadante, e aos dedicados revisores do presente trabalho.

\section{REFERÊNCIAS BIBLIOGRÁFICAS}

ARCT, J.; OBORSKA, A.; MOJSKI, M.; BINKOWSKA, A.; SWIDZIKOWSKA, B. Common cosmetic hydrophilic ingredients as penetration modifiers of flavonoids. Int. J. Cosmet. Sci., Oxford, v. 24, n.6, p.357$366,2002$.

BABY, A.R.; LACERDA, A.C.L.; KAWANO, Y.; VELASCO, M.V.R.; LOPES, P.S.; KANEKO, T.M. Evaluation of the interaction of surfactants with stratum corneum model membrane from Bothrops jararaca by DSC. Int. J. Pharm., Amsterdam, v.317, n.1, p.7-9, 2006b.

BABY, A.R.; LACERDA, A.C.L.; KAWANO, Y.; VELASCO, M.V.R.; LOPES, P.S.; KANEKO, T.M. Spectroscopic studies of stratum corneum model membrane from Bothrops jararaca treated with cationic surfactant. Colloid. Surf. B Biointerfaces, Amsterdam, v.50, n.1, p.61-65, 2006c.

BABY, A.R.; LACERDA, A.C.L.; KAWANO, Y.; VELASCO, M.V.R.; KANEKO, T.M. PAS-FTIR and FT-Raman qualitative characterization of sodium dodecyl sulfate interaction with an alternative stratum corneum model membrane. Pharmazie, Eschborn, v.62, n.10, p.727-731, $2007 \mathrm{~b}$.

BABY, A.R.; LACERDA, A.C.L.; PINTO, C.A.S.O.; LOPES, P.S. ; VELASCO, M.V.R.; KANEKO, T.M. Métodos biofísicos empregados na análise do estrato córneo. Lat. Am. J. Pharm., Buenos Aires, v.27, n.1, p.124-130, 2008.

BABY, A.R.; MACIEL, C.P.M.; KANEKO, T.M.; VELASCO, M.V.R. UV spectrophotometric determination of bioflavonoids from a semisolid pharmaceutical dosage form containing Trichilia catigua Adr. Juss (and) Ptychopetalum olacoides Bentham standardized extract: analytical method validation and statistical procedures. J. AOAC Int., Gaithersburg, v.89, n.6, p.1532-1537, 2006 . 
BABY, A.R.; MIGLIATO, K.F.; MACIEL, C.P.M.; ZAGUE, V.; PINTO, C.A.S.O.; SALGADO, H.R.N.; KANEKO, T.M.; VELASCO, M.V.R. Accelerated chemical stability data of $\mathrm{O} / \mathrm{W}$ fluid emulsions containing the extract of Trichilia catigua Adr. Juss (and) Ptychopetalum olacoides Bentham. Rev. Bras. Cienc. Farm., São Paulo, v.43, n.3, p.405-412, 2007a.

BENTLEY, M.V.L.B.; KEDOR, E.R.M.; VIANNA, R.F.; COLLETT, J.H. The influence of lecithin and urea on the in vitro permeation of hydrocortisone acetate through skin hairless mouse. Int. J. Pharm., Amsterdam, v.146, n.2, p.255-262, 1997.

BRASIL. Resolução R.E. n.899, de 29 de maio de 2003. Determina a publicação do "Guia para validação de métodos analíticos e bioanalíticos". Disponível em: $<$ http:/ / e - le g i s.bvs.br/1 e is ref/publi c/ showAct.php?id=15132\&word $>$. Acesso em: 26 jan. 2004.

BRASIL. Ministério da Saúde. Agência Nacional de Vigilância Sanitária. Guia de estabilidade de produtos cosméticos. Brasília, 2004. v.1, 45p.

BRUNETON, J. Elementos de fitoquímica y de farmacognosia. Zaragoza: Acribia, 1991. 594p.

CASAGRANDE, R.; GEORGETTI, S.R.; VERRI JR., W.A.; BORIN, M.F.; LOPEZ, R.F.V.; FONSECA, M.J.V. In vitro evaluation of quercetin cutaneous absorption from topical formulations and its functional stability by antioxidant activity. Int. J. Pharm., Amsterdam, v.328, n.2, p.183-190, 2007.

CAUSON, R. Validation of chromatographic methods in biomedical analysis: view point and discussion. $J$. Chromatogr., B, Biomed. Sci. Appl., Amsterdam, v.689, n.1, p.175-180, 1997.

FEINBERG, M.; RAGUÈNÈS, N. Development and application of a standardized validation procedure for food chemistry laboratories. Anal. Chim. Acta, Amsterdam, v.391, n.2, p.239-252, 1999.

FLORENCE, A.T.; ATTWOOD, D. Physicochemical principles of pharmacy. 2.ed. Oxford: Macmillan, 1988. p.132-171.

FRIEDMAN, M.; JÜRGENS, H.S. Effect of $\mathrm{pH}$ on the stability of plant phenolic compounds. J. Agric. Food Chem., Easton, v.48, n.6, p.2101-2110, 2000.
GIL-ALEGRE, M.E.; BERNABEU, J.A.; CAMACHO, M.A.; TORRES-SUAREZ, A.I. Statistical evaluation for stability studies under stress storage conditions. Farmaco, Pavia, v.56, n.11, p.877-883, 2001.

GUY, R.H.; KALIA, Y.N.; DELGADO-CHARRO, B.; MERINO, V.; LÓPEZ, A.; MARRO, D. Iontophoresis: electrorepulsion and elctroosmosis. J. Control. Release, Amsterdam, v.64, n.1/3, p.129-132, 2000.

HADGRAFT, J. Skin deep. Eur. J. Pharm. Biopharm., Amsterdam, v.58, n.2, p.291-299, 2004.

HADGRAFT, J. Skin, the final frontier. Int. J. Pharm., Amsterdam, v.224, n.1/2, p.1-18, 2001.

HADGRAFT, J.; RIDOUT, G. Development of model membranes for percutaneous absorption measurements. I. Isopropyl myristate. Int. J. Pharm., Amsterdam, v.39, n.1/2, p.149-156, 1987.

HAIGH, J.M.; BEYSSAC, E.; CHANET, L.; AIACHE, J.M. In vitro permeation of progesterone from a gel through the shed snake skin of three different species. Int. J. Pharm., Amsterdam, v.170, n.2, p.151-156, 1998.

HAIGH, J.M.; SMITH, E.W. The selection of natural and synthetic membranes for in vitro diffusion experiments. Eur. J. Pharm. Sci., Amsterdam, v.2, n.5/6, p.311-330, 1994.

ICH Q2B. Department of Health and Human Services. Food and Drug Administration. Center for Drug Evaluation Research. Guidance for industry: Validation of analytical procedures: methodology. Rockville, 1995. (CPMP/ICH/ 281/95). Disponível em: <http://www.fda.gov/cber/gdlns/ ichq2bmeth.pdf $>$. Acesso em: 26 jan. 2006.

IDSON, B. Stability testing of emulsions: part 2. Drug Cosmet. Ind., New York, v.152, n.2, p.38-43, 72, 1993.

ITOH, T.; MAGAVI, R.; CASADY, R.L.; NISHIHATA, T.; RYTTING, J.H. A method to predict the percutaneous permeability of various compounds: shed snake skin as a model membrane. Pharm. Res., New York, v.7, n.12, p.1302-1306, 1990b.

ITOH, T.; XIA, J.; MAGAVI, R.; NISHIHATA, T.; RYTTING, J.H. Use of shed snake skin as a model membrane for in vitro percutaneous penetration studies: comparison with human skin. Pharm. Res., New York, v.7, n.10, p.1042-1047, 1990a. 
JENKE, D.R. Chromatographic method validation: a review of current practices and procedures. II. Guidelines for primary validation parameters. J. Liq. Chromatogr. Relat. Technol., Philadelphia, v.19, n.5, p.737-757, 1996.

KASSAB, N.M.; SINGH, A.K.; KEDOR-HACKMAM, E.R.M.; SANTORO, M.I.R.M. Quantitative determination of ciprofloxacin and norfloxacin in pharmaceutical preparations by high performance liquid chromatography. Rev. Bras. Cienc. Farm., São Paulo, v.41, n.4, p.507-513, 2005.

LI, B.; BIRT, D.F. In vitro and in vivo percutaneous absorption of cancer preventive flavonoid apigenin in different vehicles in mouse skin. Pharm. Res., New York, v.13, n.11, p.1710-1715 1996.

MAIA, A.M.; BABY, A.R.; PINTO, C.A.S.O.; YASAKA, W.J.; SUENAGA, E.; KANEKO, T.M.; VELASCO, M.V.R. Influence of sodium metabisulfite and glutathione on the stability of vitamin $\mathrm{C}$ in $\mathrm{O} / \mathrm{W}$ emulsion and extemporaneous aqueous gel. Int. J. Pharm., Amsterdam, v.322, n.1/2, p.130-135, 2006.

MAIA, A.M.; BABY, A.R.; PINTO, C.A.S.O.; YASAKA, W.J.; SUENAGA, E.; KANEKO, T.M.; VELASCO, M.V.R. Validation of HPLC stability-indicating method for vitamin $\mathrm{C}$ in semisolid pharmaceutical/cosmetic preparations with glutathione and sodium metabisulfite, as antioxidants. Talanta, Amsterdam, v.71, n.2, p.639-643, 2007.

MEGRAB, N.A.; WILLIAMS, A.C.; BARRY, B.W. Oestradiol permeation across human skin, silastic and snake skin membranes: the effects of ethanol/water cosolvent systems. Int. J. Pharm., Amsterdam, v.116, n.1, p.101-112, 1995.

MONTENEGRO, L.; CARBONE, C.; MNISCALCO, C.; LAMBUSTA, D.; NICOLOSI, G.; VENTURA, C.A.; PUGLISI, G. In vitro evaluation of quercetin-3-O-acyl esters as topical prodrugs. Int. J. Pharm., Amsterdam, v.336, n.2, p.257-262, 2007.

MOSER, K.; KRIWET, K.; NAIK, A.; KALIA, Y. N.; GUY, R.H. Passive skin penetration enhancement and its quantification in vitro. Eur. J. Pharm. Biopharm., Amsterdam, v.52, n.2, p.103-112, 2001.
NAIK, A.; KALIA, Y.N.; GUY, R.H. Transdermal drug delivery: overcoming the skin's barrier function. Pharm. Sci. Technol. Today, Oxford, v.3, n.9, p.318-326, 2000.

OECD. Organization for Economic Co-operation and Development. Environment Health and Safety Publications. Draft Guidance Document for the Conduct of Skin Absorption Studies. Paris: OECD, 2000. 28p. (Series on Testing and Assessment N. 28).

PONGJANYAKUL, T.; PRAKONGPAN, S.; PANOMSUK, S.; PUTTIPIPATKHACHORN, S.; PRIPREM, A. Shed king cobra and cobra skins as model membranes for invitro nicotine permeation studies. J. Pharm. Pharmacol., London, v.54, n.10, p.1345-1350, 2002.

REICHLING, J.; LANDVATTER, U.; WAGNER, H.; KOSTKA, K.H.; SCHAEFER, U.F. In vitro studies on release and human skin permeation of Australian tea tree oil (TTO) from topical formulations. Eur. J. Pharm. Biopharm., Amsterdam, v.64, n.2, p.222-228, 2006.

RIBANI, M.; BOTTOLI, C.B.G.; COLLINS, C.H.; JARDIM, C.F.S.; MELO, L.F.C. Validação em métodos cromatográficos e eletroforéticos. Quim. Nova, São Paulo, v.27, n.5, p.771-780, 2004.

RIGG, P.C.; BARRY, B.W. Shed snake skin and hairless mouse skin as a model membrane for human skin during permeation studies. J. Invest. Dermatol., Baltimore, v.94, n.2, p.235-240, 1990.

ROLIM, A.; MACIEL, C.P.M.; KANEKO, T.M.; CONSIGLIERI, V.O.; SALGADO-SANTOS, I.M.N.; VELASCO, M.V.R. Validation assay for total flavonoids, as rutin equivalents, from Trichilia catigua Adr. Juss (Meliaceae) and Ptychopetalum olacoides Bentham (Olacaceae) commercial extract. J. AOAC Int., Gaithersburg, v.88, n.4, p.1015-1019, 2005.

ROTHWELL, J.A.; DAY, A.J.; MORGAN, M.R.A. Experimental determination of octanol-water partition coefficients of quercetin and related flavonoids. J. Agric. Food Chem., Easton, v.53, n.11, p.4355-4360, 2005.

SAIJA, A.; TOMAINO, A.; TROMBETTE, D.; GIACCHI, M.; DE PASQUALE, A.; BONINA, F. Influence of different penetration enhancers on in vitro skin permeation and in vivo photoprotective effect of flavonoids. Int. J. Pharm., Amsterdam, v.175, n.1, p.85-94, 1998. 
SCHMOOK, F.P.; MEINGASSNER, J.G.; BILLICH, A. Comparison of human skin or epidermis models with human and animal skin in in-vitro percutaneous absorption. Int. J. Pharm., Amsterdam, v.215, n.1/2, p.51-56, 2001.

TAKAHASHI, K.; TAMAGAWA, S.; KATAGI, T.; RYTTING, J.H.; NISHIHATA, T.; MIZUNO, N. Percutaneous permeation of basic compounds through shed snake skin as a model membrane. J. Pharm. Pharmacol., London, v.45, n.10, p.882-886, 1993.

TROMMER, H.; NEUBERT, R.H.H. Overcoming the stratum corneum: the modulation of skin penetration. Skin Pharmacol. Physiol., New York, v.19, n.2, p.106-121, 2006.

TURUNEN, T.M.; BÜYÜKTIMKIN, S.; BÜYÜKTIMKIN, N.; URTTI, A.; PARONEN, P.; RYTTING, J.H. Enhanced delivery of 5-fluorouracil through skin by two new transdermal penetration enhancers. Int. J. Pharm., Amsterdam, v.92, n.1/3, p.89-95, 1993.

UNITED States Pharmacopeia: USP27; The National Formulary: NF22. Rockville: United States Pharmacopeial Convention, 2003. p.2622-2625.
VALENTA, C.; NOWACK, E.; BERNKOP-SCHNÜRCH, A. Deoxycholate-hydrogels: novel drug carrier systems for topical use. Int. J. Pharm., Amsterdam, v.185, n.1, p.103-111, 1999.

VELASCO, M.V.R.; BALOGH, T.S.; PEDRIALI, C.A.; SARRUF, F.D.; PINTO, C.A.S.O.; KANEKO, T.M.; BABY,A.R. Associação da rutina com $p$-metoxicinamato de octila e benzofenona-3: avaliação in vitro da eficácia fotoprotetora por espectrofotometria de refletância. Lat. Am. J. Pharm., Buenos Aires, v.27, n.1, p.23-27, 2008.

WALKER, R.B.; SMITH, E.W. The role of percutaneous penetration enhancers. Adv. Drug Deliv. Rev., Amsterdam, v.18, n.3, p.295-301, 1996.

WIDLER, N.; SIGRIST, A.; GAFNER, F.M. Lipid analysis and transepidermal water loss in snakes. IFSCC Magazine, Augsburg, v.5, n.1, p.24-29, 2002.

WILLIAMS, A.C.; BARRY, B.W. Penetration enhancers. Adv. Drug Delivery Rev., Amsterdam, v.56, n.5, p.603618, 2004

ZATZ, J.L. Skin permeation. Fundamentals and application. Wheaton: Allured Publishing Corporation, 1993. 300p.

Recebido para publicação em 30 de agosto de 2007 Aceito para publicação em 18 de março de 2008 